\title{
Eficiência microbiana e parâmetros ruminais em bovinos alimentados com dietas à base de volumosos tropicais
}

\author{
Luciano da Silva Cabral ${ }^{1 *}$, Sebastião de Campos Valadares Filho ${ }^{2}$, Edenio Detmann ${ }^{1}$, Joanis \\ Tilemahos Zervoudakis ${ }^{1}$, Alexandre Lima de Souza ${ }^{1}$, Rafael Gonçalves Veloso ${ }^{1}$
}

\footnotetext{
${ }^{1}$ Programa de Pós-graduação em Zootecnia - UFV, Viçosa-MG, CEP: 36571-000.

2 DZO/CCA-UFV, Av. P. H. Rolphs, s/n, Viçosa-MG, CEP: 36571-000.
}

RESUMO - Objetivou-se com este trabalho determinar o fluxo de compostos nitrogenados no abomaso, a degradação ruminal dos carboidratos totais e da matéria orgânica, a eficiência microbiana, a concentração de $\mathrm{N}-\mathrm{NH}_{3}$ e o $\mathrm{pH}$ ruminal em bovinos alimentados com dietas à base de silagem de milho, silagem de capim-elefante ou feno de capim-tifton 85 Foram utilizados seis bovinos fistulados no rúmen e abomaso em um delineamento quadrado latino $3 \times 3$ duplo. Os fluxos de matéria seca da digesta e da matéria seca microbiana no abomaso foram determinados a partir da utilização de fibra em detergente neutro indigestível e das bases purinas como indicador microbiano, respectivamente. As concentrações de $\mathrm{NH}_{3}$ e o pH ruminal foram determinados antes e 2, 4 e 8 horas após a alimentação. As dietas à base de silagem de milho e de feno de capim-tifton 85 proporcionaram os maiores fluxos de compostos nitrogenados no abomaso. As bactérias isoladas do rúmen apresentaram em média $8,89 \%$ de $\mathrm{N}$ total e 18,40 para a relação N-RNA:N-total. A dieta à base de silagem de milho promoveu maior degradação ruminal da matéria orgânica (2,96 kg/dia) e dos carboidratos totais (3,07 kg/dia) e maior fluxo de massa microbiana para o abomaso (788,28 g/dia). As dietas à base de feno de capim-tifton 85 e de silagem de capim-elefante resultaram em maior eficiência microbiana, cujos valores foram 28,10 e 30,39 g de $\mathrm{N}$ microbiano/kg de carboidratos degradados no rúmen. As menores concentrações de $\mathrm{NH}_{3}$ e $\mathrm{pH}$ ruminal, considerando o tempo após a alimentação, ocorreram quando fornecida a dieta à base de silagem de milho, o que possivelmente afetou negativamente a eficiência microbiana.

Palavras-chave: capim-elefante, feno de tifton, $\mathrm{NH}_{3}$ e $\mathrm{pH}$ ruminal, proteína microbiana, silagem de milho

\section{Microbial efficiency and ruminal parameters in cattle fed diets based on tropical forage}

\begin{abstract}
The objectives of the present work were to determine nitrogen compounds flow into the abomasum, total carbohydrate and organic matter ruminal degradation, microbial efficiency, $\mathrm{N}-\mathrm{NH}_{3}$ concentration and ruminal $\mathrm{pH}$ in cattle fed with diets based on corn silage, elephant grass silage and Tifton-85 bermudagrass hay. Six ruminal and abomasal fistulated cattle were utilized in a double $3 \times 3$ latin square. Abomasal digesta dry matter of and microbial dry matter flows were determined by use of indigestible neutral detergent fiber and base purines as microbial marker, respectively. The $\mathrm{N}-\mathrm{NH}_{3}$ concentration and ruminal $\mathrm{pH}$ were determined before and 2, 4 and 8 hours after feeding. The diets based on corn silage and Tifton-85 bermudagrass hay provided higher nitrogen compounds flow into abomasum. Isolated bacteria from rumen averaged $8.89 \%$ of total $\mathrm{N}$ and had an N-RNA:N-total ration of 18.40 . The corn silage diet provided higher ruminal degradation of organic matter $(2.96 \mathrm{~kg} / \mathrm{day})$ and of total carbohydrates $(3.07 \mathrm{~kg} /$ day $)$ and higher microbial matter flow to the abomasum (788.28 g/day). The Tifton-85 bermudagrass hay and elephant grass silage diets had the greatest microbial efficiencies, which values were 28.10 and $30.39 \mathrm{~g}$ of microbial $\mathrm{N} / \mathrm{kg}$ of rumen degradable carbohydrates. The corn silage diet showed lower $\mathrm{N}-\mathrm{NH}_{3}$ concentration and ruminal $\mathrm{pH}$ after feeding, possibly indicating reduction of microbial efficiency.
\end{abstract}

Key Words: corn silage, elephantgrass, microbial protein, ruminal $\mathrm{pH}$ and $\mathrm{NH}_{3}$, Tifton hay

\section{Introdução}

O rúmen-retículo é o principal local de digestão dos componentes dietéticos nos ruminantes, ação exercida pela numerosa e diversa população microbiana deste compartimento (Van Soest, 1994).

Considerando que o crescimento microbiano no rúmen está associado à capacidade digestiva do animal e influencia

Este artigo foi recebido em 1/9/2006 e aprovado em 6/11/2007.

Correspondências devem ser enviadas para cabralls@cpd.ufmt.br.

*Endereço atual: FAMEV-UFMT, Av. Fernando Corrêa da Costa, s/n, Coxipó, Cuiabá-MT, CEP: 78060-900. 
a produção de AGV e o fluxo de proteína microbiana para o intestino delgado, têm sido realizados estudos no sentido de obter melhor entendimento dos fatores que o limitam (Nocek \& Russell, 1988; Hoover \& Stokes, 1991).

A eficiência microbiana pode ser representada pela produção de células microbianas (número ou massa) sintetizadas por unidade de substrato utilizada. Nos sistemas de exigências nutricionais de ruminantes, a eficiência microbiana pode ser expressa como função do NDT (NRC, 2001), da energia metabolizável fermentescível (AFRC, 1993) ou da disponibilidade de carboidratos no rúmen (Russell et al., 1992).

Dos fatores que afetam a eficiência microbiana, destacam-se: a disponibilidade e a sincronização entre energia e os compostos nitrogenados (N) (Pirt, 1965; Van Kessel \& Russell, 1996; Dijkstra et al., 1998; Russell, 1998). Considerando que em condições tropicais, os carboidratos fibrosos (CF) são a maior fonte de energia no rúmen e que as gramíneas destas regiões apresentam teores médios ou baixos de proteína, a disponibilidade de $\mathrm{N}-\mathrm{NH}_{3}$ no rúmen pode ser o principal fator limitante do crescimento microbiano neste compartimento (Nolan \& Leng, 1972).

Uma vez presente no rúmen, o $\mathrm{N}-\mathrm{NH}_{3}$ é assimilado pelos microrganismos a partir de duas rotas principais: por meio da enzima glutamato desidrogenase (GDH) e pelas enzimas glutamina sintetase e glutamato sintase (GS-GOGAT). O sistema GDH prevalece em condições de elevadas concentrações de $\mathrm{N}-\mathrm{NH}_{3}$, sem gasto de ATP. Entretanto, o GS-GOGAT atua efetivamente em baixas concentrações de $\mathrm{N}-\mathrm{NH}_{3}$, mas com gasto de ATP (Erfle et al., 1977; McSweeney et al., 1993; Morrison \& Mackie, 1996). Considerando que a produção de ATP no rúmen é relativamente baixa, as vias de assimilação dos nutrientes podem exercer grande efeito sobre a eficiência microbiana.

Portanto, objetivou-se neste trabalho determinar a eficiência microbiana, a degradação ruminal dos carboidratos totais (CT) e da matéria orgânica (MO), a concentração de $\mathrm{N}-\mathrm{NH}_{3}$ e o $\mathrm{pH}$ ruminal em bovinos alimentados com dietas à base de silagem de milho, silagem de capim-elefante ou feno de capim-tifton 85.

\section{Material e Métodos}

As dietas (Tabela 1), os animais, o delineamento experimental e a determinação dos fluxos de matéria seca (MS) abomasal foram descritos por Cabral et al. (2006). Foram utilizados seis bovinos mestiços com peso vivo médio inicial de $351 \mathrm{~kg}$, fistulados no rúmen e abomaso. O delineamento experimental utilizado foi em dois quadrados latinos $3 \times 3$, simultâneos, no qual cada período experimental teve duração de 18 dias - os dez primeiros para adaptação dos animais às dietas e os oito dias restantes para as coletas para avaliação do consumo e das digestibilidades total e parcial dos nutrientes, do $\mathrm{pH}$ e da concentração de $\mathrm{NH}_{3}$ ruminais, assim como da eficiência microbiana. Os animais foram alimentados com dietas à base de silagem de milho (SM), silagem de capim-elefante (SCE) ou feno de capim-tifton 85.

No 17 을 dia de cada período, foram realizadas coletas de amostras de fluido ruminal nos seguintes tempos: antes da alimentação e 2, 4, 6 e 8 horas depois para mensuração do $\mathrm{pH}$ e determinação da concentração de $\mathrm{N}-\mathrm{NH}_{3}$. O pH foi medido imediatamente após a coleta do fluido ruminal por meio de um potenciômetro digital. Em seguida, $50 \mathrm{~mL}$ de fluido foram acondicionados em frasco contendo $1 \mathrm{~mL}$ de solução 1:1 de ácido sulfúrico e mantidos a $-5^{\circ} \mathrm{C}$.

As amostras de líquido ruminal foram descongeladas para determinação da concentração de $\mathrm{N}-\mathrm{NH}_{3}$ por meio de sua destilação com solução de hidróxido de potássio (KOH) 2N, conforme descrito por Vieira (1980). O fluxo de compostos nitrogenados não-amoniacais no abomaso foi quantificado pela diferença entre o $\mathrm{N}$ total e o $\mathrm{N}-\mathrm{NH}_{3}$ presentes na digesta abomasal. A degradação ruminal dos CT e da MO foi determinada utilizando-se a fibra insolúvel em detergente neutro indigestível (FDNI), obtida in vitro, como indicador do fluxo da digesta para o abomaso, conforme relatado por Cochram et al. (1986).

Para determinação da composição microbiana e do fluxo de MS microbiana no abomaso, no 18 o dia de cada período experimental, foram coletados $2 \mathrm{~L}$ de conteúdo ruminal de cada animal para o isolamento de bactérias (Cecava et al., 1990). As bases purínicas foram utilizadas como indicadores microbianos e sua determinação nas bactérias e na digesta abomasal foi feita conforme descrito por Ushida et al. (1985). A quantidade de compostos microbianos no abomaso foi determinada pelo fluxo de N-RNA no abomaso dividido pela relação N-RNA: $\mathrm{N}$-total das bactérias isoladas do rúmen. Assim, foi possível quantificar o fluxo de MS e proteína microbiana no abomaso.

O experimento foi analisado segundo um delineamento em quadrado latino duplo $3 \times 3$, de acordo com o seguinte modelo estatístico:

$$
\mathrm{Y}_{\mathrm{ijkl}}=\mu+\mathrm{Q}_{\mathrm{i}}+\mathrm{T}_{\mathrm{j}}+\mathrm{P}_{\mathrm{k}}+\mathrm{A}_{(\mathrm{i}) \mathrm{l}}+\mathrm{QT}_{\mathrm{ij}}+\mathrm{e}_{\mathrm{ijkl}}
$$

em que: $\mu=$ constante geral; $Q_{i}=$ efeito do quadrado latino $\mathrm{i} ; \mathrm{T}_{\mathrm{j}}=$ efeito do tratamento ou à dieta $\mathrm{j} ; \mathrm{P}_{\mathrm{k}}=$ efeito da linha ou do período $\mathrm{k} ; \mathrm{A}_{(\mathrm{i}) \mathrm{l}}=$ efeito de coluna ou animal $\mathrm{l}$, aninhado ao quadrado latino $\mathrm{i} ; \mathrm{QT}_{\mathrm{ij}}=$ efeito da interação entre o quadrado latino i e o tratamento $j$; $e_{i j k l}=$ erro 
Tabela 1 - Composição das dietas experimentais

\begin{tabular}{lccc}
\hline \multirow{2}{*}{ Item } & \multicolumn{3}{c}{ Dieta (\% MS) } \\
\cline { 2 - 4 } & $\begin{array}{c}\text { Silagem } \\
\text { de milho }\end{array}$ & $\begin{array}{c}\text { Silagem de } \\
\text { capim-elefante }\end{array}$ & $\begin{array}{c}\text { Feno de capim- } \\
\text { tifton } 85\end{array}$ \\
\hline PB $^{1}$ & 11,33 & 10,63 & 10,66 \\
Matéria mineral $^{1}$ & 5,79 & 10,65 & 6,73 \\
EE $^{1}$ & 2,39 & 1,52 & 1,38 \\
$\mathrm{CT}^{1}$ & 80,47 & 71,20 & 82,63 \\
FDN $^{1}$ & 52,08 & 69,03 & 80,02 \\
FDNcp $^{1}$ & 48,92 & 63,07 & 73,72 \\
CNF $^{1}$ & 31,56 & 14,13 & 8,90 \\
FDNI $^{1}$ & 17,43 & 29,43 & 35,40 \\
\hline
\end{tabular}

$1 \%$ na matéria seca.

$\mathrm{CT}$ = carboidratos totais; FDN = fibra insolúvel em detergente neutro; FDNcp = FDN corrigida para cinzas e proteína; CNF = carboidratos nãofibrosos; FDNI = FDN indigestível.

aleatório, pressuposto erro normalmente e independentemente distribuído (NID) $\left(0, \sigma^{2}\right)$.

$\mathrm{O}$ valor da estatística $\mathrm{F}$ para tratamento foi calculado pela razão entre os quadrados médios para tratamentos e a interação quadrado latino $\times$ tratamentos. A comparação entre médias foi realizada por meio do teste de StudentNewman-Keulls (SNK), adotando-se $\alpha=0,05$.

As análises estatísticas para as variáveis $\mathrm{pH}$ ruminal e concentração ruminal de $\mathrm{N}-\mathrm{NH}_{3}$ foram realizadas pela subdivisão das parcelas de acordo com os tempos de avaliação.

\section{Resultados e Discussão}

As dietas à base de silagem de milho (SM) e feno de capim-tifton 85 (FCT), em razão do maior consumo de MS (Cabral, 2002), proporcionaram maior ingestão de $\mathrm{N}$ que a silagem de capim-elefante (SCE) (Tabela 2). Conseqüentemente, o fluxo de $\mathrm{N}$ total no abomaso e o de $\mathrm{N}$ não-amoniacal (NNA) foram superiores para as duas primeiras dietas.

Considerando a relação $\mathrm{N}$ total no abomaso/ $\mathrm{N}$ total ingerido, para a dieta à base de silagem de milho, $97 \%$ do $\mathrm{N}$ total consumido alcançou o abomaso, enquanto, para as dietas à base de FCT e SCE, os valores foram de 89 e $88 \%$ e permitem inferir que essas dietas com FCT e SCE proporcionaram menores recuperações de $\mathrm{N}$ no abomaso em relação ao consumido, indicando maiores efluxos de $\mathrm{N}$ do rúmen.Esses resultados podem ser explicados pela falta de sincronização na degradação ruminal da proteína e dos carboidratos, pois, nestes volumosos, os CF representam a principal fonte de energia no rúmen.Os elevados valores observados para a concentração $\mathrm{N}-\mathrm{NH}_{3}$ no líquido ruminal para as dietas à base de FCT e SCE reforçam a hipótese anterior, pois a baixa concentração de energia de rápida fermentação (Tabela 1) nestas duas dietas retardou a utilização do $\mathrm{N}$ no rúmen, culminando com elevados valores para o $\mathrm{N}-\mathrm{NH}_{3}$.
Tabela 2 - Compostos nitrogenados $(\mathrm{N})$ ingeridos presentes no abomaso e nas fezes de bovinos alimentados com dietas à base de silagem de milho (SM), silagem de capim-elefante (SCE) ou feno de capim-tifton 85 (FCT)

\begin{tabular}{|c|c|c|c|c|}
\hline \multirow[t]{2}{*}{ Item } & \multicolumn{3}{|c|}{ Dieta (\% MS) } & \multirow[t]{2}{*}{$\mathrm{CV}(\%)$} \\
\hline & SM & FCT & SCE & \\
\hline \multicolumn{5}{|c|}{ Quantidade de N (g/dia) } \\
\hline $\mathrm{N}$ total ingerido & $122,04 \mathrm{a}$ & $110,26 a$ & $85,08 b$ & 13,40 \\
\hline $\mathrm{N}$ total no abomaso & $119,29 a$ & $98,84 \mathrm{a}$ & $74,78 b$ & 26,88 \\
\hline $\mathrm{N}-\mathrm{NH}_{3}$ no abomaso ${ }^{1}$ & 6,00 & 9,07 & 6,23 & 61,89 \\
\hline NNA no abomaso ${ }^{2}$ & 113,13 & 89,77 & 69,06 & 30,86 \\
\hline $\mathrm{N} \mathrm{Mic} \mathrm{no} \mathrm{abomaso}^{3}$ & 67,25 & 55,22 & 53,14 & 17,50 \\
\hline $\mathrm{N}$ total na fezes & $34,10 \mathrm{a}$ & $29,74 a$ & $22,84 b$ & 17,21 \\
\hline
\end{tabular}

Embora existam diferenças numéricas, não foi detectada diferença estatística para o fluxo de $\mathrm{N}$ microbiano no abomaso para as dietas avaliadas. A proporção de $\mathrm{N}$ microbiano no abomaso em relação ao NNA foi de 59, 61 e 77\% para as dietas à base de SM, FCT e SCE. Embora o valor médio de $65,66 \%$ de N microbiano em relação ao NNA no abomaso esteja um pouco abaixo do valor de $73,6 \%$ observado por Klusmeyer et al. (1990) e de 80,72\% encontrado por Cardoso et al. (2000) foi próximo ao valor médio de $61,5 \%$ verificado por Dias (2000). A maior proporção numérica, para esta variável, observada para a dieta à base de SCE pode ser atribuída à elevada porcentagem de seu N total ser NNP, o qual é rapidamente utilizado no rúmen. Adicionalmente, o baixo consumo de MS resultou em elevado tempo de residência dos nutrientes no rúmen, aumentando sua degradação ruminal e fazendo com que o $\mathrm{N}$ microbiano represente a maior proporção do $\mathrm{N}$ no abomaso.

$\mathrm{A}$ excreção fecal de $\mathrm{N}$ foi superior para as dietas à base de SM e FCT em relação à de SCE, em virtude, possivelmente, de sua maior ingestão, uma vez que não houve diferença quanto à digestão do $\mathrm{N}$ para os alimentos.

Não foram verificadas diferenças quanto ao teor de MO, N-total, CT e N-RNA relacionadas às dietas, com exceção do teor de EE, que foi superior para as bactérias oriundas dos animais submetidos à dieta de SCE (Tabela 3 ). O teor de MO observado nas bactérias foi inferior aos valores de 91,07 e 89,2\% obtidos por Cardoso et al. (2000) e Valadares Filho (1995), respectivamente, mas próximo ao valor de 77,5\% descrito por Clark et al. (1992). Esse fato pode ser atribuído à contaminação com a solução salina durante o processo de isolamento. Desta forma, os valores de $\mathrm{N}$ total foram expressos com base na MO, portanto, foram próximos aos verificados por vários autores (Dias et al., 2000; Cardoso 
Tabela 3 - Teores de matéria seca (MS), matéria orgânica (MO), compostos nitrogenados $(\mathrm{N})$, extrato etéreo (EE), carboidratos totais $(\mathrm{CT})$ e $\mathrm{N}-\mathrm{RNA}$ e relação $\mathrm{N}$-RNA:N-total das bactérias isoladas do rúmen de bovinos alimentados com dietas à base de silagens de milho (SM) e capim-elefante (SCE) ou feno de capim-tifton 85 (FCT)

\begin{tabular}{lrrrrr}
\hline \multirow{2}{*}{ Item } & \multicolumn{3}{c}{ Dieta } & Média & CV (\%) \\
\cline { 2 - 4 } & \multicolumn{1}{c}{ SM } & \multicolumn{1}{c}{ FCT } & \multicolumn{1}{c}{ SCE } & & \\
\hline MS (\%) & 85,16 & 85,13 & 84,72 & 85,00 & - \\
MO $^{1}$ & 73,53 & 71,55 & 73,64 & 72,90 & 6,31 \\
N (\%MO) & 8,52 & 9,47 & 8,68 & 8,89 & 9,38 \\
EE $^{1}$ & 3,42 & 2,72 & 4,04 & 3,39 & 17,70 \\
CT $^{1}$ & 32,07 & 28,86 & 30,24 & 30,39 & 13,31 \\
N-RNA & 1,62 & 1,63 & 1,65 & 1,63 & 5,00 \\
N-RNA:N (\% MO) & 19,00 & 17,21 & 19,01 & 18,40 & \\
\hline
\end{tabular}

$1 \%$ na MS.

et al., 2000). Com base nisso, a relação média N-RNA:N-total observada expressa na base da MO, foi de 18,40, acima da maioria dos trabalhos realizados no Brasil.

Embora não-significativo, as bactérias oriundas do rúmen dos animais alimentados com dieta à base de SM apresentaram numericamente maior teor de CT. Essa tendência pode ser atribuída ao elevadoteor de CNF na dieta, os quais, por serem de rápida fermentação ruminal, tendem a ser armazenados pelas bactérias, principalmente quando há limitação de $\mathrm{N}$ no rúmen, o que pode ser confirmado pelos menores valores de $\mathrm{NH}_{3}$ ruminal (Figura 1).

A degradação ruminal dos CT e da MO, em kg/dia, bem como a eficiência microbiana, são apresentados na Tabela 4. A degradação ruminal dos CT e da MO foi superior para a dieta à base de silagem de milho em relação às outras duas dietas, uma vez que esta apresentouelevado teor de $\mathrm{CNF}$, os quais, por apresentarem rápida taxa de digestão ruminal (Cabral et al., 2004), tendem a ser quase completamente digeridos no rúmen, sendo muito pouco afetados pela variação na taxa de passagem. Conseqüentemente, o fluxo de MS microbiana no abomaso, embora sem diferença significativa, foi 28 e $32 \%$ maior para a dieta à base de SM que para as dietas à base de SCE e de FCT, respectivamente.

A degradação ruminal dos $\mathrm{CT}$ para a dieta à base de FCT foi ligeiramente superior à da SCE. Apesar disso, o fluxo de massa microbiana foi numericamente superior para a dieta SCE provavelmente em virtude da melhor sincronização entre $\mathrm{N}$ e energia no rúmen, pois as taxas de digestão estimadas para os $\mathrm{CF}$ e CNF do feno de capim-tifton 85 foram ligeiramente inferiores às estimadas para a silagem de capimelefante (Cabral et al., 2004).

A eficiência microbiana, em qualquer forma de expressão, foi inferior para a dieta à base de silagem de milho,
Tabela 4 - Matéria orgânica degradada no rúmen (MODR), carboidratos totais digeridos no rúmen (CTDR), matéria seca microbiana no abomaso (MS mic.) e eficiência microbiana em bovinos dietas à base de silagem de milho (SM), silagem de capim-elefante (SCE) ou feno de capim-tifton 85 (FCT)

\begin{tabular}{lrrrr}
\hline Item & \multicolumn{3}{c}{ Dieta } & CV (\%) \\
\cline { 2 - 4 } & SM & FCT & \multicolumn{1}{c}{ SCE } \\
\hline MODR (kg) & $3,07 \mathrm{a}$ & $1,96 \mathrm{~b}$ & $1,77 \mathrm{~b}$ & 17,27 \\
CTDR (kg) & $2,96 \mathrm{a}$ & $1,78 \mathrm{~b}$ & $1,62 \mathrm{~b}$ & 18,34 \\
MS microbiana (g) & $788,28 \mathrm{a}$ & $592,72 \mathrm{a}$ & $614,55 \mathrm{a}$ & 20,84 \\
g de MS microbiana/ & $253,36 \mathrm{~b}$ & $299,81 \mathrm{a}$ & $351,57 \mathrm{a}$ & 22,17 \\
kg CTDR & & & & \\
g N microbiano/kg MODR & $21,59 \mathrm{~b}$ & $28,10 \mathrm{a}$ & $30,39 \mathrm{a}$ & 20,44 \\
g N microbiano/kg MODR & $22,62 \mathrm{~b}$ & $32,31 \mathrm{a}$ & $34,03 \mathrm{a}$ & 28,36 \\
g PB microbiana/kg NDT & $97,11 \mathrm{~b}$ & $105,14 \mathrm{~b}$ & $135,22 \mathrm{a}$ & 12,34 \\
\hline
\end{tabular}

Valores seguidos com letras sobrescritas diferentes na mesma linha diferem $(P<0,05)$ entre si pelo teste SNK.

enquanto a eficiência da dieta de SCE foi próxima daquela descrita pelo NRC (2001), de 130 g de PB microbiana/kg de NDT.

Hoover \& Stokes (1991), por meio de estudos com fermentadores contínuos e com vacas de leite, verificaram que, apesar de o acréscimo de CNF na dieta ter acarretado aumento da digestão ruminal dos CT, não teve qualquer efeito sobre a eficiência microbiana. Entretanto, a eficiência microbiana respondeu linearmente ao aumento de proteína degradada no rúmen. Considerando que a dieta à base de $\mathrm{SM}$ apresentou teor elevado de CNF e que o teor protéico da dieta foi moderado, pode-se inferir que a eficiência microbiana foi limitada pela disponibilidade de $\mathrm{N}$, o que pode ser confirmado pelas baixas concentrações de $\mathrm{N}$ amoniacal (Figura 1). Nesta condição, como a energia não era limitante, provavelmente os microrganismos utilizaram uma parcela desta energia nas reações de "Energy Spilling”, como tentativa de dissipar o excesso de energia (Van Kessel \& Russell, 1996; Russell, 1998). Além disso,o requisito de mantença dos microrganismos que fermentam CNF é de $0,15 \mathrm{~g}$ de carboidrato/g de célula/hora, três vezes maior que a dos microrganismos fermentadores de CF $(0,05 \mathrm{~g}$ carboidrato/g célula/hora) (Russell et al., 1992). Assim, considerando que o crescimento microbiano na dieta à base de silagem de milho foi limitado pela disponibilidade de $\mathrm{N}$, o requisito de mantença pode ter representado grande proporção no total de energia utilizada pela célula.

Considerando que a proteína é o componente microbiano de maior interesse pelos nutricionistas de ruminantes e que a composição microbiana pode ser alterada com os fatores dietéticos, Nocek \& Russell (1988) sugeriram que a eficiência microbiana fosse expressa com base no $\mathrm{N}$ microbiano sintetizado, pois, desta forma, as variações relacionadas à composição das células tendem a serem 
minimizadas. Adicionalmente, como os carboidratos são a principal fonte de energia para os microrganismos (Russell et al., 1992), a eficiência microbiana provavelmente seja mais corretamente expressa em relação aos carboidratos totais digeridos no rúmen.

Russell et al. (1992), a partir dos requisitos de mantença dos microrganismos e das respectivas taxas de crescimento, calcularam o máximo rendimento teórico dos microrganismos como de 0,4 $\mathrm{g}$ de massa microbiana/g carboidrato fermentado.

Entretanto, na literatura nacional e internacional, valores maiores que 0,5 (500 g de massa microbiana/kg de carboidrato) para a eficiência microbiana têm sido observados, possivelmente em virtude de variações metodológicas utilizadas para a determinação dos fluxos de MS abomasal. Entretanto, neste estudo, a eficiência microbiana média foi de 0,3 (300 g de massa microbiana/kg de carboidrato digerido) e, embora pareça muito baixa, quando expressa como g de $\mathrm{N}$ microbiano/kg CTDR, foi próxima dos valores observados por Vieira et al. (2000), que variaram de 19 a $30 \mathrm{~g}$ de $\mathrm{N}$ microbiano/kg de CTDR.

As equações de regressão que melhor se ajustaram aos dados foram:

$$
\begin{gathered}
\hat{\mathrm{Y}} \mathrm{NH}_{3}=8,24+2,59 \mathrm{~T}-0,3645 \mathrm{~T}^{2}(\mathrm{SM}) ; \\
\hat{\mathrm{Y}} \mathrm{NH}_{3}=10,15+7,32 \mathrm{~T}-0,8647 \mathrm{~T}^{2}(\mathrm{FCT}) ; \\
\hat{\mathrm{Y}} \mathrm{NH}_{3}=7,13+8,84 \mathrm{~T}-0,9399 \mathrm{~T}^{2}(\mathrm{SCE}) .
\end{gathered}
$$

Foram verificadas diferenças significativas quanto à concentração de $\mathrm{N}-\mathrm{NH}_{3}$ ruminal nos tempos em função da dieta (Figura 1). Para a dieta à base de silagem de milho, foram detectadas as menores concentrações, o que é atribuído à rápida utilização pelos microrganismos que fermentam CNF. Foram estimadas concentrações máximas de $\mathrm{N}-\mathrm{NH}_{3}$ ruminal de $12,84 \mathrm{mg} / \mathrm{dL}$ às 3,55 horas após a alimentação, de 25,64 mg/dL às 4,23 horas e de 27,91 mg/dL às 4,7 horas, respectivamente, para as dietas à base de $\mathrm{SM}$, de FCT e de SCE.

Para as dietas à base de FCT e de SCE, as concentrações de $\mathrm{N}-\mathrm{NH}_{3}$ obtidas 4 horas após a alimentação mantiveram-se acima de $20 \mathrm{mg} / \mathrm{dL}$ de fluido ruminal e depois reduziram para 14 e $18 \mathrm{mg} / \mathrm{dL} 8$ horas depois. Essas concentrações de $\mathrm{N}-\mathrm{NH}_{3}$ teoricamente são adequadas para atender às exigências de $\mathrm{N}$ dos microrganismos que fermentam $\mathrm{CF}$, os quais predominam no rúmen. Desta forma, pode-se inferir que o crescimento microbiano foi limitado pela disponibilidade de energia, a qual era, em sua maioria, oriunda dos CF.

Considerando as menores concentrações de $\mathrm{N}-\mathrm{NH}_{3}$ ruminal observadas para a dieta à base de silagem de milho, pode-se inferir que a principal forma de assimilação da $\mathrm{N}-\mathrm{NH}_{3}$ pelos microrganismos ruminais provavelmentefoi

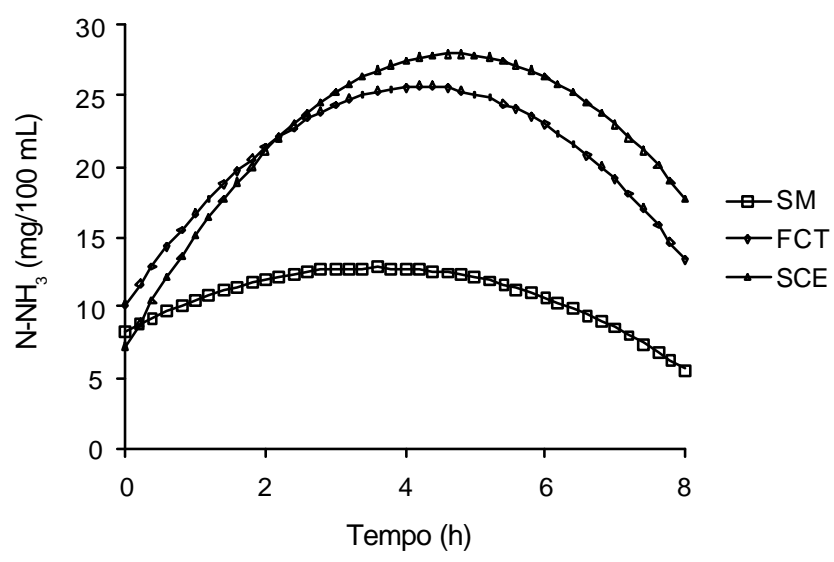

Figura 1 - Concentração de $\mathrm{NH}_{3}$ ruminal após a alimentação com dietas à base de silagens de milho (SM), silagem de capim-elefante (SCE) ou feno de capim-tifton 85 (FCT).

pela GS-GOGAT, a qual, por envolver gasto de ATP, tende a reduzir a eficiência microbiana. Desta forma, o teor protéico de dietas com silagem de milhodeve ser maior que o fornecido neste trabalho. Outra opção seria acrescentar fontes protéicas de rápida utilização ruminal no sentido de otimizar a eficiência dos microrganismos na utilização da energia disponível. O contrário pode ser dito para as dietas à base de FCT e de SCE, para as quais foram observados maiores valores para a concentração de $\mathrm{N}-\mathrm{NH}_{3}$, em que possivelmente a falta de carboidratos de rápida fermentação limitou a utilização de $\mathrm{N}$ para fins de crescimento microbiano.

Os valores de $\mathrm{pH}$ para as dietas de FCT e de SCE mantiveram-se dentro dos limites fisiológicos ao longo dos tempos de mensuração (Figura 2). Entretanto, para a dieta à base de $\mathrm{SM}$, foi atingido o pH de 6,07 no tempo 8 horas. Foram estimados para as dietas à base de silagem de milho valor de pH mínimo de 6,05 às 7,1 horas após a alimentação, e para o FCT valor máximo de 7,04 às 1,17 hora, para a dieta de SCE o comportamento foi linear.

As equações de regressão que melhor explicaram a variação no $\mathrm{pH}$ ruminal no tempo foram:

$$
\begin{gathered}
\hat{\mathrm{Y}} \mathrm{pH}=7,03-0,266 \mathrm{~T}+0,01819 \mathrm{~T}^{2}(\mathrm{SM}) ; \\
\hat{\mathrm{Y}} \mathrm{pH}=7,03+0,02231 \mathrm{~T}-0,009489 \mathrm{~T}^{2}(\mathrm{FCT}) ; \\
\hat{\mathrm{Y}} \mathrm{pH}=7,35-0,1231 \mathrm{~T}(\mathrm{SCE})
\end{gathered}
$$

Em virtude da rápida fermentação dos CNF e da alteração da população microbiana, quando os CNF são incluídos em elevadas quantidades na dieta, observa-se aumento na taxa de produção de ácidos totais, bem como o aumento da produção de ácido láctico, promovendo redução do $\mathrm{pH}$ ruminal. Desta forma, considerando que a SM é um volumoso com elevada concentração de CNF, sua utilização em dietas para ruminantes, associada a elevados níveis de concentrado, 


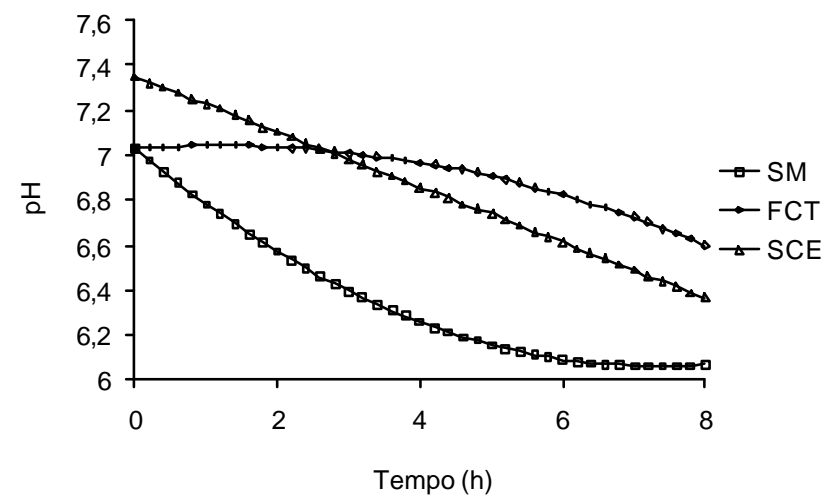

Figura 2 - pH ruminal após a alimentação com dietas à base de silagem de milho (SM), silagem de capim-elefante (SCE) ou feno de capim-tifton 85 (FCT).

pode favorecer a redução do $\mathrm{pH}$ ruminal de forma mais intensa em comparação aos outros volumosos, o que tem como conseqüências indesejáveis a redução do crescimento microbiano e da digestão da fibra, que afeta a o consumo e o desempenho animal. Em casos mais extremos, podem ocorrer ruminite, paraqueratose, abscessos no fígado, acidose sistêmica e laminite.

\section{Conclusões}

Embora as dietas à base de silagem de capim-elefante e feno de capim-tifton 85 tenham proporcionado maior eficiência microbiana, a silagem de milho permitiu maior fluxo de MS microbiana no abomaso, fator mais importante que a própria eficiência microbiana isolada. Considerando os valores para a concentração de $\mathrm{N}-\mathrm{NH}_{3}$ ruminal e a composição das dietas, pode-se inferir que a disponibilidade de compostos nitrogenados foi o principal fator limitante ao crescimento da microbiota ruminal quando fornecidas as dietas à base de silagem de milho e que a energia de rápida fermentação foi o principal fator limitante nas dietas à base de silagem de capim-elefante e feno de capim-tifton 85. Estas considerações poderão nortear a adequação de dietas utilizando os volumosos avaliados neste trabalho, no sentido de promover o aumento do crescimento microbiano ruminal e do fluxo de proteína microbiana para o abomaso.

\section{Literatura Citada}

AGRICULTURAL AND FOOD RESEARCH COUNCIL - AFRC. Energy and protein requirements of ruminants. Cambridge: $\mathrm{CAB}$ International, Cambridge University Press, 1993. 159p.

BROCK, T.D.; MADIGAN, M.T.; MARTINKO, J.M. et al. Biology of microorganisms. 7.ed. Englewood Cliffs: Prentice Hall International, 1994. 909p.
CABRAL, L.S.; VALADARES FILHO, S.C.; DETMANN, E. et al. Taxas de digestão das frações protéicas e de carboidratos para as silagens de milho e de capim-elefante, o feno de capimtifton-85 e o farelo de soja. Revista Brasileira de Zootecnia, v.33, n.6, p.1573-1580, 2004.

CABRAL, L.S; VALADARES FILHO, S.C.; DETMANN, E. et al. Consumo e digestibilidade dos nutrientes em bovinos alimentados com dietas à base de volumosos tropicais. Revista Brasileira de Zootecnia, v.35, n.6, p.2406-2412, 2006.

CARDOSO, R.C.; VALADARES FILHO, S.C.; COELHO DA SILVA, J.F. et al. Síntese microbiana, pH e concentração de amônia ruminal e balanço de compostos nitrogenados, em Novilhos $F$ Limousin x Nelore. Revista Brasileira de Zootecnia, v.29, n.6, p.1844-1852, 2000

CECAVA, M.J.; MERCHEN, N.R.; GAY, L.C. et al. Composition of ruminal bacteria harvested from steers as influenced by dietary energy level, feeding frequency and isolation techniques. Journal of Dairy Science, v.73, p.2480-2488, 1990.

CLARK, J.H.; KLUSMEYER, T.H.; CAMERON, M.R. Microbial proteins synthesis and flows of nitrogen fractions to the duodenum of dairy cows. Journal of Dairy Science, v.75, n. 8, p. 2304-2323, 1992 .

COCHRAN, R.C.; ADAMS, D.C.; WALLACE, J.D. et al. Predicting digestibility of different diets with internal markers: evaluation of four potential markers. Journal of Animal Science, v.63, n.5, p.1476-1483, 1986

DIAS, H.L.C.; VALADARES FILHO, S.C.; COELHO DA SILVA, J.F. et al. Eficiência de síntese microbiana, $\mathrm{pH}$ e concentrações ruminais de amônia em novilhos F1 Limousin x Nelore alimentados com dietas contendo cinco níveis de concentrado. Revista Brasileira de Zootecnia, v.29, n.2, p.555-563, 2000.

DIJKSTRA, J.; FRANCE, J.; DAVIES, D.R. Different mathematical approaches to estimating microbial protein supply in ruminants. Journal of Dairy Science, v.81, p.3370-3384, 1998.

ERFLE, J.D.; SAUER, F.D.; MAHADEVAN, S. Effect of ammonia concentration on activity of enzymes of ammonia assimilation and on synthesis of amino acids by mixed rumen bacteria in continuous culture. Journal of Dairy Science, v.60, p.1064-1072, 1977.

HOOVER, W.H.; STOKES, S.R. Balancing carbohydrates and proteins for optimum rumen microbial yield. Journal of Dairy Science, v.74, p.3630-3644, 1991.

KLUSMEYER, T.H.; McCARTHY, R.D.; CLARK, J.H. Effects of source and amount of protein on ruminal fermentation and passage of nutrients to the small intestine of lactating cows. Journal of Dairy Science, v.73, n.12, p.3526-3537, 1990.

McALLISTER, T.A.; BAE, H.D.; JONES, G.A. et al. Microbial attachment and feed digestion in the rumen. Journal of Animal Science, v.72, p.3004-3018, 1994.

MARTIN, S.A. Nutrient transport by ruminal bacteria: a review. Journal of Animal Science, v.72, p.3019-3031, 1994.

McSWEENEY, C.S.; MACKIE, R.I.; WHITE, B.A. Transport and intracellular metabolism of major feed compounds by ruminal bacteria: the potential for metabolic manipulation. Australian Journal of Agricultural Research, v.45, n.4, p.731-756, 1993.

MOAT, A.G.; FOSTER, J.W. Microbial physiology. 3.ed. New York: John Wiley \& Sons, 1995. 580p.

MORRISON, M.; MACKIE, R.I. Nitrogen metabolism by ruminal microorganisms: current understanding and future perspectives. Australian Journalof Agricultural Research, v.47, p.227246, 1996.

NATIONAL RESEARCH COUNCIL - NRC. Nutrient requirements of dairy cattle. 7.ed. Washington, D.C.: National Academy Press, 2001. 381p.

NOCEK, J.E.; RUSSELL, J.B. Protein and energy as an integrated system. Relationship of ruminal protein and carbohydrate availability to microbial synthesis and milk production. Journal of Dairy Science, v.71, n.8, p.2070-2107, 1988. 
NOLAN, J.V.; LENG, R.A. Dynamic aspects of ammonia and urea metabolism in sheep. British Journal of Nutrition, v.27, p.177-194, 1972 .

PIRT, S.J. The maintenance energy of bacteria in growing cultures. Proceedings of Royal Society (Series B), n.163, p.224231, 1965.

RUSSELL, J.B.; SHARP, W.M.; BALDWIN, R.L. The effect of pH on maximum bacterial growth rate and its possible role as a determinant of bacterial competition in the rumen. Journal of Animal Science, v.48, n.2, p.251-255, 1979.

RUSSELL, J.B. Another explanation for the toxicity of fermentation acids at low $\mathrm{pH}$ : anion accumulation versus uncoupling. Journal of Applied Bacteriology, v.73, p.363-370, 1992.

RUSSELL, J.B.; O'CONNOR, J.D.; FOX, D.G. et al. A net carbohydrate and protein system for evaluation cattle diets: ruminal fermentation. Journal of Animal Science, v.70, n.12, p.3551-3581, 1992.

RUSSELL, J.B. Strategies that ruminal bacteria use to handle excess carbohydrate. Journal of Animal Science, v.76, n.8, p.19551963, 1998

SATTER, L.D.; SLYTER, L.L. Effect of ammonia concentration on rumen microbial production in vitro. British Journal of Nutrition, v.32, n.2, p.199-208, 1974.

USHIDA, K.; LASSALAS, B.; JOUANY, J.P. Determination of assay parameters for RNA analysis in bacterial and duodenal samples by spectrophotometry. Influence of sample treatment and preservation. Reprodution and Nutrition Development, v.25, n.6, p.1037-1046, 1985.

VALADARES FILHO, S.C. Eficiência de síntese de proteína microbiana, degradação ruminal e digestibilidade intestinal da proteína bruta, em bovinos. In: SIMPÓSIO INTERNACIONAL SOBRE EXIGÊNCIAS NUTRICIONAIS DE RUMINANTES, 1995, Viçosa, MG. Anais... Viçosa, MG: Universidade Federal de Viçosa, 1995. p.355-388.

Van KESSEL, J.S.; RUSSELL, J.B. The effect of amino nitrogen on the energetics of ruminal bacteria and its impact on energy spilling. Journal of Dairy Science, v.79, n.7, p.1237-1243, 1996.

Van SOEST, P.J. Nutritional ecology of the ruminant. 2.ed. Ithaca: Cornell University Press, 1994. 476p.

VIEIRA, P.F. Efeito do formaldeído na proteção de proteínas e lipídeos em rações para ruminantes. Viçosa, MG: Universidade Federal de Viçosa, 1980. 98p. Tese (Doutorado em Zootecnia) - Universidade Federal de Viçosa, 1980.

VIEIRA, R.A.M.; PEREIRA, J.C.; MALAFAIA, P.A.M. et al. Simulação da dinâmica de nutrientes no trato gastrintestinal: Aplicação e validação de um modelo matemático para bovinos a pasto. Revista Brasileira de Zootecnia, v.29, n.3, p.898909, 2000. 